\title{
Effect of amygdaloid lesions on retention of an avoidance response in overtrained and non-overtrained rats'
}

\author{
ROBERT W. THATCHER ${ }^{2}$ AND DANIEL P, KIMBLE \\ UNIVERSITY OF OREGON
}

The effects of electrolytic amygdala lesions on retention of an active avoidance response were investigated in overtrained and non-overtrained rats. All overtrained rats exhibited normal retention following bilateral amygdala lesions while retention was impaired in three out of four of the nonovertrained rats in which the basolateral nuclei were damaged. These results were interpreted as supporting the hypothesis that the amygdala is primarily involved in acquisition processes and not long-term memory storage.

A deficit in acquisition of an active avoidance response, following bilateral damage to the amygdala, has been reported for rats (Robinson, 1963), cats (Brady et al, 1954; Horvath, 1963) and monkeys (Weiskrantz, 1956). Whether or not the amygdala is involved in the retention of an avoidance response, however, is still open to question. Horvath (1963) found that retention of a preoperatively acquired avoidance response was severely dismupted by bilateral amygdala lesions. Horvath's findings, however, conflict with those of Brady et al (1954), who reported that amygdala lesions had no effect on retention of an active avoidance response. Horvath suggested that the preoperative overtraining given to Brady's Ss may explain the discrepancy. He reasoned that if the amygdala is primarily involved in acquisition processes, overtraining would reduce or eliminate any deficit.

The purpose of this experiment was twofold: to investigate the effects of amygdala lesions on retention of an active avoidance response in rats; and to test Horvath's proposal by comparing the effect of amygdala lesions on the retention of overtrained versus nonovertrained avoidance responses.

Method

The Ss were experimentally naive, male albino Sprague-Dawley rats, weighing 150-195 gm at the start of the experiment.

Ss were randomly divided into two groups: nonovertrained (I) and overtrained (II). Each group was further divided into three subgroups: subgroups I-N and II-N $(\mathrm{N}=6)$ were normal controls, subgroups $\mathrm{I}-\mathrm{O}$ and II-O $(\mathrm{N}=6)$ were operated controls, and subgroups $\mathrm{I}-\mathrm{A}$ and $\mathrm{II}-\mathrm{A}(\mathrm{N}=7)$ were experimentals. Subgroup II-O was later reduced to three Ss: one died during surgery, one developed postoperative convulsions, and one failed to leam the avoidance task after 200 trials. Subgroup II-A was reduced to six as one rat failed to learn the task after 200 trials.
Ss were trained in a shuttle box (36 in. $x 6$ in. $x 22$ in.) with a grid floor. A 2-in. hurdle separated the box into two identical compartments. The CS was a buzzer located at the top of the box above the hurdle and the UCS was a .75 ma constant shock.

Ss had 10 sec. after the onset of the CS to jump the hurdle in order to avoid shock. The intertrial interval was $60 \mathrm{sec}$. during the acquisition phase of training and 45 sec. during the overtraining phase. The shock side was the side the $\mathrm{S}$ was on at the onset of the CS. All conditioning trials (including overtraining) for each $\mathrm{S}$ were given in a single day. After a $10 \mathrm{~min}$. familiarization period Ss received a block of 12 conditioning trials; thereafter conditioning trials were given in blocks of 25 with approximately $30 \mathrm{~min}$. rest periods between the blocks. The acquisition criterion was $9 / 10$ avoidance responses within a single block. For the non-overtrained Ss, conditioning trials were terminated when acquisition criterion was reached. For the overtrained Ss, an additional 120 trials were given after acquisition criterion was attained. The Ss in subgroups I $-\mathrm{O}, \mathrm{I}-\mathrm{A}, \mathrm{II}-\mathrm{O}$, and II-A underwent surgery the following day. All Ss were tested for retention of the avoidance task seven days after the training phase. The retention phase was conducted in a similar manner to the acquisition phase.

\section{Surgery and Histology}

Surgery was performed under clean conditions with Nembutal anesthesia $(52 \mathrm{mg} / \mathrm{kg})$. Bilateral electrolytic lesions were produced using a Kopf stereotaxic instrument and a König \& Klippel (1963) atlas. The

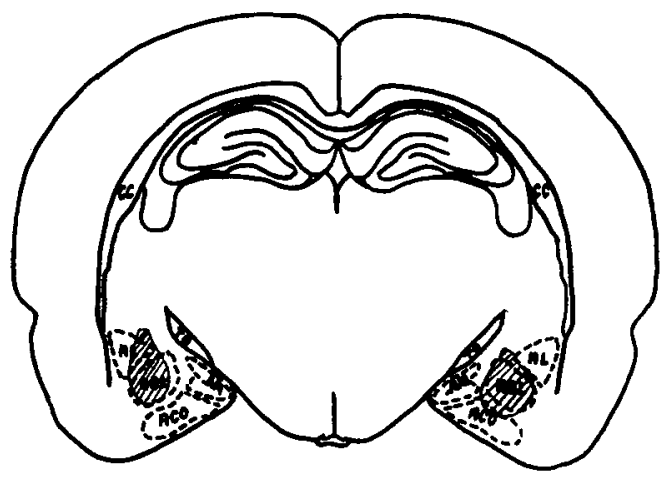

Fig. 1. Representative lesion (S I-A3) ABL-basal amygdaloid nucleus, pars lateralis; ACO - cortical amygdaloid nucleus; $A L$ lateral anygdaloid nucleus; $A M$ - medial amygdaloid nucleus. 
Table 1. Percent Savings

(Savings $=$ Trials to acquisition - trials to retention)

Trials to acquisition

\begin{tabular}{|c|c|c|c|c|}
\hline \multicolumn{2}{|c|}{ Experimentals } & \multicolumn{2}{|c|}{ Controls } & Normals \\
\hline \multicolumn{5}{|c|}{ Non-overtrained subjects } \\
\hline$*|-A|$ & $-100 \%$ & $1-09$ & $+78 \%$ & $\mathrm{I}-\mathrm{N} 17+66 \%$ \\
\hline $\mathrm{I}-\mathrm{A} 4$ & $+91 \%$ & $1-0.10$ & $+47 \%$ & I.N18+100\% \\
\hline I-A6 & $+23 \%$ & $1-011$ & $+65 \%$ & $1-N 19-15 \%$ \\
\hline |-A 15 & $+77 \%$ & 1.013 & $+30 \%$ & {$[-\mathrm{N} 21+86 \%$} \\
\hline I-A23 & $-100 \%$ & $1-07$ & $+89 \%$ & I-N22 + $80 \%$ \\
\hline $\mathrm{I}-\mathrm{A} 26$ & $+41 \%$ & $\mathrm{I}-08$ & $+65 \%$ & $\mathrm{I}-\mathrm{N} 38+40 \%$ \\
\hline$* 1-A 27$ & $-100 \%$ & & & \\
\hline \multicolumn{5}{|c|}{ Overtrained subjects } \\
\hline II-A2 & $+100 \%$ & $\mid 1-031$ & $+87 \%$ & $11-N 39+90 \%$ \\
\hline $11 . A 3$ & $+68 \%$ & $11-032$ & $+86 \%$ & $11-N 40+76 \%$ \\
\hline $11-A 5$ & $+96 \%$ & $11-036$ & $+80 \%$ & $11-N 41+89 \%$ \\
\hline II-A25 & $+66 \%$ & & & $11-N 42+91 \%$ \\
\hline II-A28 & $+93 \%$ & & & $11-N 43+93 \%$ \\
\hline $11-A 29$ & $+98 \%$ & & & $11-N 44+100 \%$ \\
\hline
\end{tabular}

* Failed to reach criterion after 200 trials

lesioning current was $2 \mathrm{ma}$ (DC) for 20 sec., with the cathodal electrode in the anus. The control operations were conducted in the same manner except that no current was passed. After completion of the experiment the lesioned Ss were killed, the brains removed, frozen, sectioned at $25 \mu$ and stained with cresyl violet.

Histology revealed that all non-overtrained Ss, with the exception of animal I-A15, received some damage to the amygdaloid complex. Ss I-A1, I-A23, I-A27, and I-A4 all received rather extensive damage to the basolateral group. S I-A6 received slight damage to the ventral edge of the basal nucleus with most of the lesion concentrated in the cortical nucleus, while S I-A26 received extensive damage to the central nucleus and slight damage to the medial portion of the lateral nucleus. The amygdala was bilaterally damaged in all overtrained Ss. The lesions were confined almost entirely to the basolateral group with Ss II-A3, II-A28, and II-A25 receiving damage also to the cortical nucleus and $\mathrm{S} I I-\mathrm{A} 29$ receiving damage also to the central nucleus.

\section{Results}

Only three of the non-overtrained Ss differed from the normal and operated controls (Table 1). All three exhibited at least $-100 \%$ retention and two of them (I-A1 and I-A23) failed to relearn the task after 200 trials. The three impaired Ss and one of the unimpaired Ss (I-A4) received extensive damage to the basolateral group, while the other three animals (I-A6, I-A26, and I-A15) failed to receive appreciable damage to these nuclei. Although there is no significant statistical difference between the amygdala group and either of the control groups, only one rat that received bilateral damage to the basolateral group exhibited adequate retention. This animal differed from all other Group I amygdala $S s$ in that while it reached acquisition criterion in 56 trials, it actively avoided in 28 of them, thus making more avoidances than all but one of the nonovertrained Ss.

Of importance is the fact that there is no significant difference between the overtrained amygdala lesion group and the two overtrained control groups.

\section{Discussion}

The results of this experiment clearly indicate that retention of a highly overtrained active avoidance response is not impaired following bilateral damage to the amygdaloid complex. A precise interpretation of the behavior of the non-overtrained Ss is more difficult. But the results do tend to implicate the basolateral amygdala nuclei as important for conditioned avoidance responding in rats. The results of this experiment also help to resolve the discrepancy between Brady et al's and Horvath's experimental findings and tend to support Horvath's interpretation. Retention in the overtrained amygdalectomized Ss was not impaired, while retention in three of the non-overtrained Ss, which received appreciable damage to the basolateral group, was disrupted.

A more specific interpretation of these findings is that the amygdala, and probably primarily the basolateral nuclei, is involved in the efficient integrative association of the CS with the appropriate avoidance response.

\section{References}

Brady, J. V., Schriener, L., Geller, I., \& Kling, A. Subcortical mechanisms in emotional behavior: the effect of rhinencephalic injury upon the acquisition and retention of a conditioned avoidance response in cats. J. comp. physiol. Psychol., 1954, 47, 178-186.

Horvath, F. E. Effects of basolateral amygdalectomy on three types of avoidance behavior in cats. J. comp. physiol. Psychol., $1963,56,380-389$.

König, J. F. R.; \& Klippel, R. A. The rat brain. A sterotaxic atlas of the forebrain and lower parts of the brain stem. Baltimore: The Williams and Wilkins Co., 1963.

Robinson, E. Effect of amygdalectomy on fear motivated behavior in rats. J. comp. physiol. Psychol., 1963, 56, 814-820.

Ursin, H. Effect of amygdaloid lesions on avoidance behavior and visual discrimination in cats. Exp. Neurol., 1965, 11, 298-317.

Weiskrantz, L. Behavioral changes with ablation of the amygdaloid complex in monkey. J. comp. physiol. Psychol., 1956, $49,381-391$.

\section{Notes}

1. The authors wish to thank John S. Buckley for his valuable assistance in collecting the data and Ruth BreMiller for the histology. This investigation was supported in part by a Public Health Service Research Grant, $\mathrm{MH}$ 08545-03 from the National Institutes of Mental Health, D. P. Kimble, principal investigator.

2. Now at the University of Waterloo, Ontario, Canada. 